\title{
A clinico-histopathological study on skin appendageal tumors
}

\author{
Paudyal $\mathrm{P}^{1}$, Agarwal M${ }^{1}$, Pradhan A ${ }^{1}$, Sinha AK ${ }^{1}$, Agrawal S \\ ${ }^{I}$ Department of Pathology, B P Koirala Institute of Health Sciences, Dharan, Nepal. \\ ${ }^{2}$ Department of Dermatology and Venerology, B P Koirala Institute of Health Sciences, Dharan, Nepal.
}

\section{Keywords: \\ Skin adnexal tumor; Pilomatricoma; Keratoacanthoma}

\begin{abstract}
Background: Skin Appendageal tumors are a large and diverse group of tumors that are commonly classified according to their state of appendageal differentiation: follicular, sebaceous, eccrine and apocrine. Objectives of this study were to study the clinic-epidemiological profile of skin appendageal tumors and to correlate the clinico-histopathological diagnosis.
\end{abstract}

Materials and Methods: This was a retrospective and prospective study which included all cases of skin adnexal tumours diagnosed histologically during the period of four and half years. Tumors were analyzed considering the anatomic location, duration, size and type of the tumour, along with age and sex of the patient. The Histological characterization was done according to the WHO classification system and was correlated with the clinical diagnosis. Collected data were analysed using SPSS PC +11.5 Version for statistical analysis.

Results: A total of 70 neoplasms of skin appendages included, 68 (97.1\%) were benign and $2(2.9 \%)$ was malignant. Female comprised of $47(67.1 \%)$ and $23(32.9 \%)$ were male. The mean age was 39.23 years. Of all, $43(61.4 \%)$ tumors were follicular, 18 (25.7\%) were eccrine, 7 (10\%) were apocrine and 2 $(2.9 \%)$ were with sebaceous differentiation. The three commonest tumors encountered in this study were Pilomatricoma (21.4\%), Keratoacanthoma (17.1\%) and Trichoepithelioma (14.3\%). Clinically, 13/70 $(18.5 \%)$ cases were diagnosed as SAT.

Conclusion: Taking histologic diagnosis as gold standard, clinical diagnosis was found to have a sensitivity of $11.08 \%$ and specificity of $77.9 \%$. Histopathology is highly significant to diagnose SAT (p $<0.011)$.

\section{INTRODUCTION}

Skin Appendageal tumors (SAT) are those neoplasms that differentiate toward or arise from pilosebaceous apparatus,

\author{
Correspondence: \\ Dr Punam Paudyal, MBBS, MD \\ Department of Pathology, B P Koirala Institute of Health Sciences, \\ Dharan, Nepal. \\ Email: punam.paudyal@bpkihs.edu
}

apocrine, and eccrine glands. Clinical diagnosis of different entity is often difficult, as most of them present as asymptomatic papules or nodules. ${ }^{1}$ Anatomic location, number and distribution of lesions provide important clue but histopathology is invaluable in confirmation of the diagnosis. ${ }^{2}$ These tumors basically originate from undifferentiated pluripotent stem cells and finally differentiate to specific tumors influenced by genetics, local vascularity, and the microenvironment of the epidermis 
Table 1: Skin adnexal tumors according to WHO classification and its frequency

\begin{tabular}{|c|c|c|c|}
\hline Character & Category & Frequency & Percentage \\
\hline \multirow{6}{*}{ Follicular Tumour } & Pilomatrixoma & 15 & 21.4 \\
\hline & Keratoacanthoma & 12 & 17.1 \\
\hline & Trichoepithelioma & 10 & 14.3 \\
\hline & Tricholemmoma & 4 & 5.7 \\
\hline & Trichofolliculoma & 1 & 1.4 \\
\hline & Trochoblastoma & 1 & 1.4 \\
\hline \multirow{2}{*}{$\begin{array}{l}\text { Sebaceous } \\
\text { Tumour }\end{array}$} & Sebaceous adenoma & 1 & 1.4 \\
\hline & Sebaceous carcinoma & 1 & 1.4 \\
\hline \multirow{9}{*}{ Eccrine Tumour } & Eccrine poroma & 4 & 5.7 \\
\hline & Hydradenoma papilliferum & 3 & 4.3 \\
\hline & Cylindroma & 2 & 2.9 \\
\hline & Chondroid syringoma & 2 & 2.9 \\
\hline & Sialadenoma papilliferum & 2 & 2.9 \\
\hline & Eccrine syringoma & 1 & 1.4 \\
\hline & Eccrine spiradenoma & 1 & 1.4 \\
\hline & Nodular hydradenoma & 2 & 2.9 \\
\hline & Adenoid cystic carcinoma & 1 & 1.4 \\
\hline \multirow{3}{*}{ Apocrine Tumour } & Apocrine hydradenoma & 2 & 2.9 \\
\hline & Apocrine mixed tumour & 1 & 1.4 \\
\hline & Syringocystadenoma Papilliferum & 4 & 5.7 \\
\hline Total & & 70 & 100.0 \\
\hline
\end{tabular}

and dermis. ${ }^{3-5}$ They are usually missed clinically and often confirmed by histopathology. ${ }^{6}$

Most SAT are benign, and local complete surgical excision is curative. However, diagnosing some of these tumors has important implications, as they might be markers for syndromes associated with internal malignancies, such as trichelemmomas in cowden disease and sebaceous tumors in Muir-Torre syndrome. ${ }^{7,8}$ A malignant counterpart of almost every SAT has been described. These tumours are rare, locally aggressive, and have the potential for nodal involvement and distant metastasis, with a poor clinical outcome. ${ }^{9}$ Therefore, establishing a diagnosis of malignancy in SAT is important for therapeutic and prognostic purposes. Because pathologists may not frequently encounter SAT, and owing to their different derivation and broad histogenesis, diagnosing these tumours may be challenging even to an experienced pathologist. ${ }^{9}$ Objectives of this study were to study the clinicoepidemiological profile of SAT and to correlate the clinico-histopathological diagnosis.

\section{MATERIALS AND METHODS}

This as a hospital based retrospective and prospective study spanning over a period of four and half years conducted in the section of histopathology. For retrospective study, all the diagnosed cases of skin appendageal tumor over a period of four years from $1^{\text {st }}$ January 2008 to $1^{\text {st }}$ January
2012 were retrieved from the indexed histopathology files of the Pathology Department, BPKIHS. The clinical data of the patients were obtained from their respective files. Prospective study was conducted over a period of six months from $1^{\text {st }}$ January 2012 to $30^{\text {th }}$ June 2012. All skin biopsies sent were fixed in $10 \%$ formalin, processed in paraffin wax and stained with Haematoxylin and Eosin and were subjected for histopathological examination. Tumors were analyzed considering histologic type, anatomic location, duration, size and type of the tumor, along with age and sex of the patient. The Histologic characterization according to the WHO classification system for skin tumors and correlation with the clinical diagnosis was done.

Collected data were entered in Microsoft Excel 2000 and converted it into SPSS PC+ 11.5 Version for statistical analysis. The descriptive statistics were presented in percentage, proportion, tabular forms and mean and standard deviation were calculated. For inferential statistics odds ratio, chi square test with p-values were calculated at the level of significant at $95 \%$, to find out the relationship between dependent variables and independent variables. Sensitivity and specificity were calculated.

\section{RESULTS}

All the patients included in this study attended BPKIHS with skin lesion. Lesions were examined clinically and were 
excised for clinico-histopathological correlation.

A total of 70 cases were studied with the age range from 7-88 years. The mean age was 39.23 year. Maximum numbers of cases were observed between the age group of 41-50 year. Among total cases, 47 (67.1\%) were female and $23(32.9 \%)$ were male patients. The most common site of predilection was head and neck region in 45 cases $(64.3 \%)$. In head and neck region scalp was the commonest site and second common site was nose. The most common duration of the lesion at the time of presentation was of 12 month followed by 6 and 1 month. Maximum numbers of lesions $(24.3 \%)$ measured were $2 \mathrm{~cm}$ in greatest diameter. The most common (44.3\%) type of lesion was nodular.

According to the WHO histological classification, they were broadly classified into four types i.e. Follicular, Sebaceous, eccrine and apocrine. Total of 70 cases studied, 68 (97.1\%) were benign and $2(2.9 \%)$ were malignant (Table 1$)$.

\section{Tumors with follicular differentiation:}

Most commonly diagnosed tumour was with follicular differentiation which constituted of 43 (61.4\%) cases. All of them were benign. Among this category the commonest tumour encountered histologically was pilomatrixoma , which constituted of 15 cases $(21.4 \%)$ of total (Table 1$)$. Histology revealed a well circumscribed nodular lesion in the dermis, surrounded by fibrous stroma along with basaloid cells lining and contiguously transforming into pale eosinophilic anucleated shadow/ ghost cells (fig. 1). Some showed multinucleated giant cells and calcification.

Most of these tumors were seen in $2^{\text {nd }}$ and $4^{\text {th }}$ decade of life, comprising of $4 / 15$ cases in each decade. In female 12/15 cases were observed and 4/15 was found to be located in scalp. None of the cases of pilomatrixoma was diagnosed clinically as pilomatrixoma. Most of them were submitted as sebaceous cyst.

Second most common tumour was keratoacanthoma, which constituted $12(17.1 \%)$ of cases. Histology revealed a central, keratin filled crater. The extension of the epidermis was seen like a lip or a buttress over the sides of the crater. At the base of the crater, irregular epidermal proliferations extend both upward into the crater and downward from the base of the crater. (fig.2) Many horn pearls were observed and the base appeared regular and well demarcated and does not extend below the level of the sweat glands.

Most of these tumors were seen in between the age of 41-50 years. There was female predominance and scalp was the commonest location. None of the cases of keratoacanthoma was diagnosed clinically as keratoacanthoma. Most of them were submitted as basal cell carcinoma.

Third common tumour was trichoepithelioma which constituted of $10(14.3 \%)$ cases. Histology revealed well circumscribed subcutaneous tumor with a normal overlying epidermis composed of lobules with anastomosing streaks of uniform basaloid cells which were without atypia; all surrounded by a fibromyxoid stroma. (fig,3) Only 2/10 cases of trichoepithelioma was diagnosed clinically as trichoepithelioma rest were diagnosed as basal cell carcinoma, nevus and papilloma.

Rest of the tumour diagnosed within follicular differentiation which did not contribute to a significant proportion of cases were trichilemmoma (1.4\%), trichofolliculoma (1.4\%), and trichoblastoma $(1.4 \%)$.

\section{Tumors with eccrine differentiation:}

Tumor with eccrine differentiation constituted of 18 cases $(25.7 \%)$ of all the total cases (Table 1). Among them 17 cases $(24.3 \%)$ were benign and 1 case $(1.4 \%)$ was malignant. Among all the benign tumors of eccrine origin the commonest tumor encountered histologically was eccrine poroma, which constituted of 4 (5.7\%) cases. Histology revealed benign neoplastic changes of sweat duct consisting of broad anastomosing bands in the deeper parts of epidermis extending to dermis. The tumour consists of sheets of uniform small cuboidal cells connected by intercellular bridges, with intervening secretion filled narrow ductal lumina lined by eosinophilic cuticle (fig. 4).

Clinically out of 4 eccrine poromas, one was diagnosed as papilloma, one as nevus and two as granulomatous lesion.

Second common tumor was hydradenoma papilliferum which constituted of $3(4.3 \%)$ cases. Rest of the benign tumour diagnosed with eccrine differentiation which did not contribute to a significant proportion of cases were cylindroma $(2.9 \%)$, chondroid syringoma $(2.9 \%)$, sialadenoma papilliferum $(2.9 \%)$, nodular hydradenoma $(2.9 \%)$, eccrine syringoma (1.4\%) and eccrine spiradenoma $(1.4 \%)$. Adenoid cystic carcinoma was the malignant eccrine tumor seen in our study.

\section{Tumors with apocrine differentiation:}

Tumor with apocrine differentiation constituted 7 cases (10 $\%$ ) of total (Table 1). All of them were benign. Among them the commonest tumor encountered was syringocystadenoma papilliferum which constituted of 4 cases (5.7\%). Histology revealed several cystic invaginations extending downward from the epidermis with numerous villus papillary projections extending into the lumen of cystic invaginations. Both the invaginations and the papillary projections are lined by a glandular epithelium consisting of two rows of cells: an outer layer of cuboidal cells (fig. 5).

Clinically $50 \%$ syringocystadenoma papilliferum was diagnosed as verrucous epidermal nevus, one as malignancy 
and one as lymphangioma. Apocrine hydradenoma (2.9\%) and apocrine mixed tumour (1.4\%) did not contribute to a significant proportion among apocrine tumors.

\section{Tumors with sebaceous differentiation:}

Tumour with sebaceous differentiation constituted only $2(2.9 \%)$ cases (Table 1$)$. Out of which, one $(1.4 \%)$ was benign i.e. sebaceous adenoma, clinically diagnosed as sebaceous cyst and one (1.4\%) was malignant i.e. sebaceous carcinoma, clinically diagnosed as meibomian carcinoma.

\section{DISCUSSION}

In 1948 in two consecutive publications, the origin of adnexal tumors of the skin and basal cell epithelioma was discussed by Lever who suggested that a majority of the adnexal tumors arise from an embryonic rest "Primary Epithelial Germ" and a few others from the eccrine germ. ${ }^{10,11}$ It is currently believed that adnexal tumors are derived from cells that have the ability to differentiate toward any of the appendages. In many lesions, the differentiation is uniform and the tumor can be recognized and categorized based on its resemblance to a normal appendage or part of it. In other cases, the pluripotent cell may differentiate toward more than one type of appendage giving rise to a tumor that contains element of two or more appendage in varying degrees of maturation. ${ }^{3}$ Various studies had been done showing these combined characteristics of adnexal tumors. ${ }^{4-6}$ In our study, though such combined nature was not detected. .

Various studies done showed the mean age for adnexal tumors is of 41.72 and 33 years..$^{9-11}$ The mean age for adnexal tumors in this study was 39.23 year, which is consistent with other studies.

In a clinico-pathologic study of skin appendageal tumors, conducted in a span of three years, out of total 33 cases, 23 were females and 10 were males. 12 In the study conducted by Saha A et al females (65.21\%) outnumbered males $(34.78 \%){ }^{13}$ In our study also, females outnumbered males.

In this study 66 cases (97.1\%) were benign and only 2 (2.9 $\%$ ) cases were malignant. The commonest tumor was with follicular differentiation followed by eccrine differentiation and most of them were located in head and neck region and were benign. Similarly, in a study conducted by Yagoob et al, total of 166 skin appendage tumors studied, $87.3 \%$ were benign, while $12.6 \%$ were malignant. All tumors showed a predilection for occurrence on skin of head and neck $(48.1 \%)$, followed by upper limb (10.9\%) and lower limb (10.9\%). Out of total, $41.56 \%$ showed pilosebaceous differentiation, $37.34 \%$ showed eccrine differentiation, $14.45 \%$ showed apocrine differentiation and, $6.62 \%$ exhibited mixed differentiation. ${ }^{14}$ Similarly in the study conducted by Samilo MO et al, in total of 52 adnexal tumors seen, 46 were benign and 6 were malignant. Most of the lesions were distributed in head and neck region and were of follicular differentiation. ${ }^{15}$

In a clinicopathologic study on SAT carried out by Song KY et al, pilomatricoma was the most common benign tumor consisting of 72/244 (30.1\%) cases. ${ }^{16}$ Similarly in a study done by Yaqoob et al. on tumours of pilo-sebaceous unit found that plomatricoma was one of the five most common skin adnexal tumor, other being nodular hidradenoma, syringocystadenoma papilleferum, eccrine poroma and eccrine spiradenoma. ${ }^{14}$

Although uncommon, Pilomatricoma, are quite common among all pilar tumors. ${ }^{1}$ Pilomatricoma, also known as a calcifying epithelioma of Malherbe, is a benign skin tumor derived from the hair matrix. ${ }^{16}$ It was initially thought to be a sebaceous gland neoplasm. In 1961, Forbis and Helwig, after histochemical and electron microscopic analysis of 228 tumors, found the cell of origin to be the outer root sheath cell of the hair follicle. ${ }^{17}$ They are single skincoloured or purplish lesions arise on the head and neck, but they may occur on any site. ${ }^{19,11}$ The finding is comparable to this study, where the commonest site for pilomatricoma was scalp.

In this study out of 15 cases, 12 cases occurred in females while 3 occurred in males. A female preponderance is noted in majority of the studies. ${ }^{16-18}$

In the study done by Zaman $\mathrm{S}$ et al, maximum numbers of pilomatricoma were observed in $2^{\text {nd }}$ and $3^{\text {rd }}$ decades. ${ }^{19}$ In our study the maximum number of pilomatricoma were diagnosed in second to fourth decade of life. In contrast, most of the studies concluded that 1-20 years was the most affected age group. ${ }^{20,21}$ Although pilomatricoma can develop in patients of any age, children and adults are most commonly affected. ${ }^{19}$

The size of the pilomatricoma in our study ranges from $0.5-3 \mathrm{~cm}$ in maximum diameter, mean size being $1.57 \mathrm{~cm}$. The most typical clinical picture of pilomatrixoma is the occurrence of a solitary, small, firm nodule, covered with normal skin, varying in size from 5 to $30 \mathrm{~mm} .{ }^{22}$

Keratoacanthoma is a common skin lesion that occurs most often as solitary tumor in sun exposed areas in elderly. ${ }^{23} \mathrm{In}$ this study also, it is seen as the 2nd most common tumor (12/70 cases), occurring in elderly (5/12) and commonly seen in face (4/12) and scalp (3/12).

Trichoepithelioma can be a single or multiple. This is a harmless benign tumour that arises on the face after puberty. ${ }^{24}$ The tumours are small (usually $<1 \mathrm{~cm}$ ), firm, rounded and shiny. They may be yellow, pink, brown or bluish. They usually gradually increase in number with age, occurring on both cheeks, eyelids and around the nose. ${ }^{9}$ In the study done 


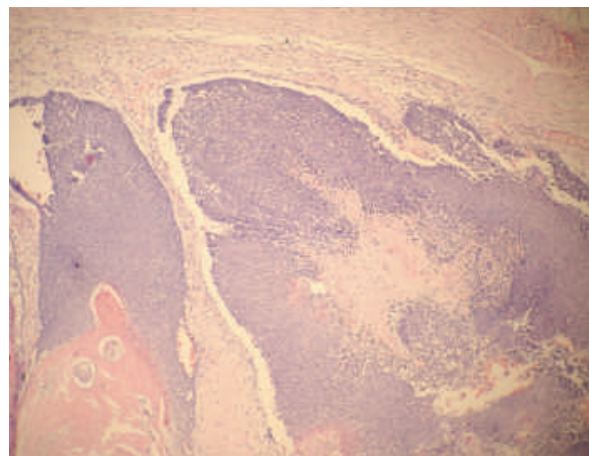

Figure 1: Basaloid cells transforming into pale, eosinophilic, anucleated ghost cells in Pilomatricoma (H\&E stain, X 100).

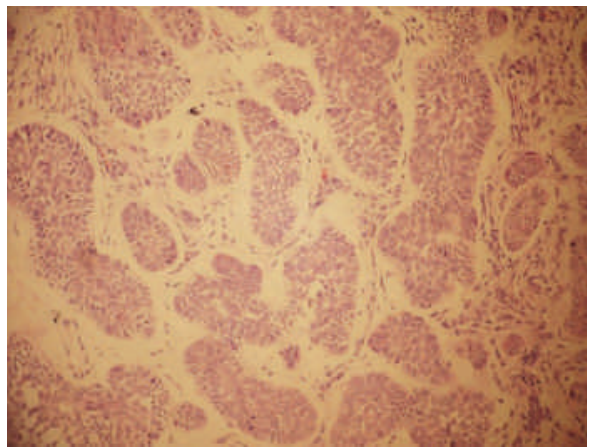

Figure 3: Trichoepithelioma with lobules of anastomosing streaks of uniform basaloid cells (H\&E stain, X 100).

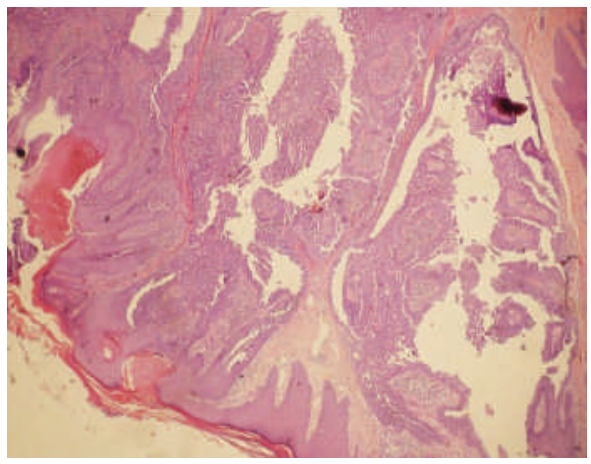

Figure 5: Villus papillary projections extending into the lumen of cystic invaginations in SCP (H\&E stain, X 100).

by Saha A et al the second most common tumour seen was Trichoepithelioma. ${ }^{13}$ In our study also Trichoepithelioma was found to be the third commonest tumor

In our study 6/10 cases of Trichoepithelioma were distributed around nose. According to the various studies, Trichoepithelioma remains primary differential diagnosis of adnexal tumors centred around nose. ${ }^{9,13,24}$

Clinically as well as histologically Trichoepithelioma

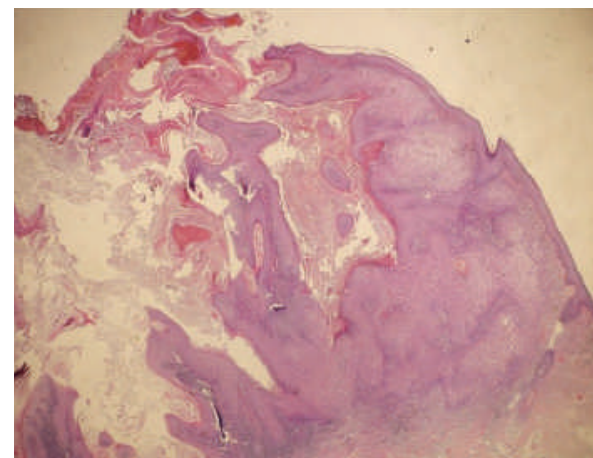

Figure 2: Central, keratin filled crater and extension of the epidermis like a lip or a buttress over the side of the crater in Keratoacanthoma (H\&E stain, X 40).

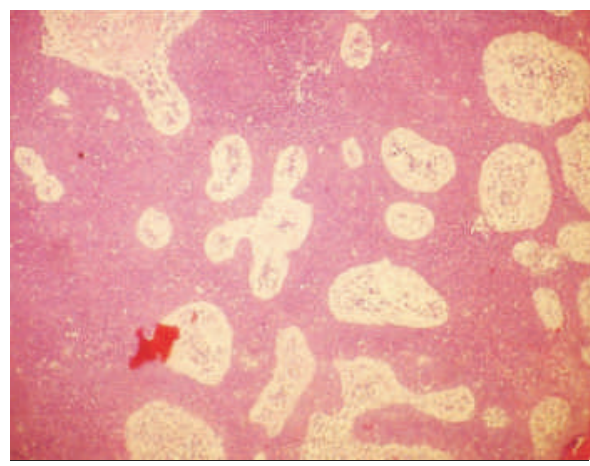

Figure 4: Sheets of uniform small cuboidal cells connected by intercellular bridges, with intervening secretion filled narrow ductal lumina in eccrine poroma (H\&E stain, X 40).

is considered in the differential diagnosis of Basal cell carcinoma. ${ }^{24}$ This could be the fact that most of the Trichoepitheliomas were clinically diagnosed as Basal cell carcinoma in this study.

Eccrine and apocrine tumors are less common group of tumors. In our study eccrine tumors constituted of 18/70 cases, the most common contribution was made by eccrine poroma ( $4 / 18$ cases), followed by hydradenoma papilliferum (3/18 cases). The term eccrine poroma was originally described by Goldman et al in 1956 to refer to a benign tumor of the sweat gland consisting of epithelial cells with eccrine type distal tubular differentiation. ${ }^{25}$ However, many authors suggest the term can be used to refer to both eccrine and apocrine. ${ }^{26,27}$

Clinically, it tends to present as a solitary tumor most frequently on the plantar surface of the foot in adult patients. However, the clinical characteristics can vary widely, with diagnosis as small pink colored papules, large verrucous plaques, or exophytic nodules in a range of sizes and locations. ${ }^{25}$

In this study also it was found in adult patient with female predominance. Only one case was located on the foot and correct diagnosis of eccrine poroma could not be made on clinical evaluation. Eccrine poroma should be considered 
in the differential diagnosis of chronic foot lesions. The differential diagnosis of such condition includes pyogenic granuloma, seborrhoeic keratosis, fibroma, melanoma, adenexal cysts, vascular tumours, basal cell and squamous cell carcinoma. ${ }^{27}$

Among seven apocrine group of tumors syringocystadenoma papilliferum constituted the major portion i.e. 4/7 cases, followed by apocrine hydradenoma i.e. 2/7 cases. Syringocystadenoma papilliferum is a hamartomatous malformation of the skin, which is believed to derive from apocrine sweat glands. However a few may derive from eccrine sweat glands, so the histogenesis remains controversial. ${ }^{28}$ Syringocystadenoma papilliferum is an exceedingly rare neoplasm often occurs in association with nevus sebaceous. Almost half are present at birth and or appear during infancy. It commonly arises at the time of puberty or less commonly, during adolescence or adult life. $^{29}$

They are found mainly in body folds including the axillary, groin and anogenital regions, where apocrine glands are most concentrated, as well as in the umbilicus, eyelid (Moll's glands), areola and in external auditory meatus. ${ }^{30} \mathrm{In}$ this study $2 / 4$ of syringocystadenoma papilliferum found to be located in the eye lid and arose predominantly at the time of puberty in female. Clinically $2 / 4$ of syringocystadenoma papilliferum were diagnosed as squamous cell carcinoma, one as nevus sebaceous and one as lymphangioma.

Syringocystadenoma papilliferum with sebaceous differentiation are uncommon, difficult to classify, and may be controversial. The main controversy concerns the microscopic features, which vary from well to poorly differentiated and sometimes undifferentiated varieties. When patients with numerous sebaceous adenomas and other neoplasms with sebaceous differentiation have an associated internal malignancy, the clinical condition is known as Muir-Torre syndrome. ${ }^{7,8}$ However, in our study, tumors with sebaceous differentiation did not contribute to a significant proportion, so such association was not observed.

\section{CONCLUSION}

This is a small study conducted on a hospital based sample at BPKIHS, Dharan, eastern part of Nepal, but it may be pertinent to summarize the important findings as follows:

1 Among seventy SATs studied, commonest tumors are those of follicular origin.

2. Among follicular tumors, PM and TE were the commonest tumors observed.

3. They are commonly distributed in the head, neck and trunk with female predominance.
4. Malignant adnexal tumors are uncommon in our setting.

5. Taking histologic diagnosis as gold standard, clinical evaluation was found to have a sensitivity and specificity of $11.8 \%$ and $77.9 \%$ respectively.

6. Histopathology is found to be a highly significant to diagnose SAT $(\mathrm{p}<0.011)$.

\section{Acknowledgement}

The authors are very grateful to all faculties, junior residents and technical staffs for their constant support and Mr. Dharanidhar Baral who helped in data collection. I extend my heartfelt thanks to all the participants of this study without whom this study would not have been completed.

\section{REFERENCES}

1. Rudolph P. Benign adnexal skin tumors. Pathologue 2002; 23:71-8. http://dx.doi.org/10.1007/s00292-001-0506-0

2. Rodriguez-Diaz E, Armio M. Mixed tumors with follicular differentiation: complex neoplasms of the primary epithelial germ. Int J Dermatol1995;34:782-5 Crossref

3. Mehregan AH. The origin of the adnexal tumors of the skin: A viewpoint. J Cutan Pathol 1985;12:459-67. Crossref

4. Wong TY, Suster S, Cheek RF, Mihm MC Jr. Benign cutaneous adnexal tumors with combined folliculosebaceous, apocrine and eccrine differentiation: Clinicopathological and immunohistochemical study of eight cases. Am J Dermatopathol 1996;18:124-8. Crossref

5. Brownstein MH. The genodermatology of adnexal tumors. J Cutan Pathol 1984;11:457-65. Crossref

6. Penneys NS. Immunohistochemistry of adnexal neoplasms. J Cutan Pathol 1984;11:357-60. Crossref

7. Matsuda K, Doi T, Kosaka H, Tasaki N, Yoshioka H, Kakibuchi M. Sebaceous carcinoma arising in nevus sebaceus. J Dermatol 2005; 32: 641-4. Crossref

8. Ansai S, Mihara I. Sebaceous carcinoma arising on actinic keratosis. Eur J Dermatol 2000;10:385-8. Crossref

9. Storm CA, Seykora JT. Cutaneous adnexal neoplasms. Am J Clin Pathol 2002;118:33-49.

10. Lever WF. Pathogenesis of benign tumors of cutaneous appendages and basal cell epithelioma. Arch Derm Syph 1948;57:679. Crossref

11. Elder D, Elenitsas R, Ragsdale BD. Tumors of the epidermal appendages. In: Elder D, Elenitsas R, Jaworsky C, Johnson B Jr, editors. Lever's Histopathology of the Skin. 8 th ed. Philadelphia: 
Lippincott Williams and Wilkins; 1997. p.747-803.

12. Nair PS. A clinicopathologic study of skin appendageal tumors. Indian J Dermatol Venerol Leprol 2008;74:550. Crossref

13. Saha A, Das NK, Gharami RC, et al. A clinico-Histopathological Study Of Appendageal Skin Tumours, affecting Head and Neck Region in Patients Attending the Dermatology OPD Of a tertiary care centre in Eastern India. Ind J Dermatol 2011;56:33-6. Crossref

14. Yaqoob N, Ahmad Z, Muzaffar S, Gill MS, Soomro IN and Hasan SH. Spectrum of cutaneous appendages tumours at Agha Khan University Hospital. J Pak Med Assoc 2003;53:427-31. Crossref

15. Samaila MO. Adnexal skin tumors in Zaria, Nigeria. Ann Afr Med 2008 7:6-10. Crossref

16. Song KY, Yoon DH, Ham EK, Lee YS. Clinico Pathological study on the skin appendageal tumors. Korean J Pathol 1989;23:111-21.

17. Forbis R and Helwig EB. Pilomatrixoma (Calcifying epithelioma). Arch Dermatol 1961;83:606-617. Crossref

18. Alsaad KO, Obaidat NA and Ghazarian D. Skin adnexal neoplasm part 1: An approach to tumours of the pilosebaceous unit. J Clin Pathol 2007; 60:129-144. Crossref

19. Zaman S, Majeed S, Rehman F. Pilomatricoma- study on 27 cases and review of literature. Biomedica 2009;25:69-72.

20. Duflo S, Nicollas R, Roman S, Magalon G, nad Triglia JM. Pilomatrixoma of the head and neck in children; a study of 38 cases and a review of the literature. Arch Otolaryngol Head Neck Surg 1998;124:1239-42. Crossref
21. Lan MY, Lan MC, Ho CY, Li WY and Lin CZ. Pilomatrixoma of the head and neck in children: A retrospective review of 179 cases. Arch Otolaryngol Head Neck Surg 2003;129:1327-10. Crossref

22. Julian CG, Bowers PW. A clinical review of 209 pilomatrixomas. J Am Acad Dermatol 1998;39:191-5. Crossref

23. Fisher B.K., Elliot G.B. Keratoacanthoma: Reflections on an Unusual Lesion. Can Med Assoc J 1965;93: 272-3. Crossref

24. Brooke H. Epithelioma adenoids cysticum. Br J Dermatol 1892;4:269.

25. Goldman P, Pinkus H, Rogin JR. Eccrine poroma; tumors exhibiting features of the epidermal sweat duct unit. Arch Derm 1956;74:51121. Crossref

26. Harvell JD, Kerschmann RL, LeBoit PE. Eccrine or apocrine poroma? Six poromas with divergent adnexal differentiation. Am j Dermatpathol 1996;18:1-9. Crossref

27. Wong MW, Tse GM. Eccrine poroma: a differential diagnosis in chronic foot lesions. Foot Ankle Int 2003;24:789-92. Crossref

28. Yamamato O, Doi $\mathrm{Y}$, Hamada $\mathrm{T}$ et al. An Immunohistochemical and ultrstructural study of syringocystadenoma papilliferum. Br J dermatol 2002;147:936-45. Crossref

29. Pinkus H. Life history of nevus syringocystadenomatous papilliferus. Arch dermatol syphil 1954;69:305-22. Crossref

30. Honma N, Takubo K, Akiyama F. et al. Expression of GCDFP $\square 15$ and AR decreases in larger or node $\square$ positive apocrine carcinomas of the breast. Histopathology 2005 47:195-201 Crossref 